\title{
АНАЛИЗ МАТЕМАТИЧЕСКИХ МЕТОДОВ УПРАВЛЕНИЯ КРУПНОЙ ОБРАЗОВАТЕЛЬНОЙ СИСТЕМОЙ
}

\section{ANALYSIS OF MATHEMATICAL METHODS OF MANAGING A LARGE EDUCATIONAL SYSTEM}

\section{A. Morgunov \\ O. Romashkova}

Summary: The article analyzes the possibilities of applying existing mathematical methods of managing a large educational system, identifies and classifies the most effective of them. These methods allow the most accurate, with a high degree of reliability to solve the tasks set in the work of the educational organization.

Keywords: regional educational system, education management, rating assessment, mathematical methods of management, informatization of education.
Моргунов Александр Игоревич

Соискатель, ГАОУ ВО «Московский городской педагогический университет» г. Москва

alex-260693@mail.ru

Ромашкова Оксана Николаевна

Д.т.н., nрофессор, ГАОУ ВО «Московский городской педагогический университет», г. Москва ox-rom@yandex.ru

Аннотация: В приведенной статье проанализированы возможности применения существующих математических методов управления крупной образовательной системой, определены и классифицированы наиболее эффективные из них. Данные методы позволяют наиболее точно, с высокой степенью достоверности решить поставленные в работе образовательной организации задачи.

Ключевые слова: региональная образовательная система, управление образованием, рейтинговое оценивание, математические методы управления, информатизация образования.

фективности использования ресурсов.

Эффективное управление образовательной системой напрямую зависит от оптимальности принимаемых решений и точности их реализации. В процессе поиска оптимальных решений недостаточно использовать только интуицию и профессиональный опыт. Для этого нужно применять эффективные методы, а также пользоваться грамотно подобранными инструментами принятия управленческих решений. Поиск оптимальных решений требует использования соответствующих методов и инструментов принятия управленческих решений. Они позволяют находить наилучшие решения, сравнивать их между собой, выбирать решения, которые максимально соответствуют имеющимся условиям и требованиям, и на основе полученных результатов вырабатывать управляющие воздействия [4].

Основным инструментом оптимизации принятия решений являются математические методы. Математические методы позволяют анализировать основные факторы, влияющие на качество решений, выполнять операции с ними и формировать выверенные, научно обоснованные рекомендации по повышению эффективности управления образовательной системой [5].

\section{Анализ математических методов управления крупной образовательной системой}

Использование математических методов в управлении эффективностью образовательной системы позво- 
ляет решить ряд практических задач [6]:

- упорядочение информации о функционировании системы;

- обеспечение оперативности и точности расчетов показателей, необходимых для повышения эффективности управления системой образования;

- проведение достоверного и углубленного количественного анализа показателей;

- выполнение многостороннего анализа факторов, влияющих на эффективность функционирования системы образования;

- оценивание результатов управляющих воздействий;

- выполнение математического прогнозирования последствий внедрения управляющих воздействий;

- выполнение математического моделирования управляемой системы с целью апробации различных условий ее функционирования.

На сегодняшний день не существует единой классификации методов оценки эффективности функционирования крупных образовательных систем. Однако, большинство математических методов, используемых в управлении эффективностью, основывается на методах теории принятия решений.

Как правило, набор используемых математических методов формируется исходя из вида и целей функционирования управляемой системы образования, а также с учетом факторов, влияющих на ее эффективность. В этом случае представляется логичным сделать упор именно на те методы, использование которых способствует реализации ключевых функций системы управления эффективностью.

К методам, использование которых способствует реализации основных функций управления эффективностью системы образования: планированию, анализу и принятию решений, можно отнести следующие:

1. Методы теории принятия решений представляют собой совокупность математических методов, помогающих принять обоснованное решение, а также способов достижения желаемого результата.

2. Метод сбалансированной системы показателей - система измерения эффективности работы системы образования, которую применяют для планирования, контроля и корректировки реализации плана.

3. Методы экспертных оценок помогают установить группе экспертов цели и проблемы, а также объекты изучения, необходимые технологии, процедуры и т.д.

4. Метод структуризации целей предусматривает создание или формулирование новых, связанных между собой целей функционирования системы образования, для выработки количественных и качественных определений, а также сроков достижения целей.

5. Метод математического моделирования представляет собой комплекс методик изучения системы, либо объекта, с помощью создания и анализа их математических моделей.

6. Методы математической статистики являют совокупность методов описания, анализа статистической информации, касательно совокупности объектов.

7. Метод «дерево целей» используется для получения полной и максимально устойчивой иерархической структуры параметров и факторов функционирования системы образования (целей, ограничений, рисков, направлений и т.д.).

8. Метод трендового анализа используют для определения динамики изменения показателей и прогнозирования значений показателей. В данном методе каждая из позиций текущих показателей сравнивается со значением этих показателей за предыдущие периоды.

9. Метод факторного анализа применяется для исследования воздействия разных факторов на результаты функционирования работы системы образования.

10. Метод регрессионного анализа подразумевает изучение существующих взаимосвязей между одной постоянной величиной и совокупностью факторов, влияющих на неё.

11. Метод корреляционного анализа. Данный метод анализирует статистическую взаимозависимость между двумя или более величинами.

12. Метод кластерного анализа подразумевает нахождение в большом количестве изучаемых свойств и объектов, таких, которые можно объединить в группы, называемые кластерами.

Каждый этап процесса управления образовательной системой требует применения определённых математических методов $[7,8]$. Представленный перечень не является однозначным, так как используемые математические методы могут варьировать как в плане состава, так и в плане применения: один и тот же этап управления эффективностью образовательной системы может использовать как комплекс различных математических методов, так и один математический метод может быть использован на различных этапах эффективного управления крупной образовательной системой.

Анализ целесообразности применения определённых математических методов в управлении образовательной системой носит эмпирический характер. Он подлежит корректировке в зависимости от свойств управляемой системы, её целей, ресурсов для достижения цели, внутренних и внешних факторов влияния. 
Задача эффективного управления крупной образовательной системой является многокритериальной, и в общем случае не имеет тривиального решения. Далее приведены этапы управления крупной образовательной системой, а также математические методы для реализации каждого этапа. Их использование наиболее целесообразно при реализации каждого этапа процесса управления эффективностью образовательными системами.

\section{Этап 1}

Постановка целей функционирования системы. На данном этапе происходит формулировка целей функционирования и развития системы, формирование системы показателей эффективности. Наиболее подходящие методы - сбалансированная система показателей (BSC), программно-целевой метод, метод «дерева целей», методы структуризации целей, кластерный анализ, методы математической статистики, метод экспертных оценок, корреляционный анализ.

\section{Этап 2}

Моделирование. Моделирование факторов, определяющих достижение поставленных целей, а также имеющихся ограничений и рисков. Для реализации данного этапа подходят методы математического моделирования, факторный анализ, регрессионный анализ, корреляционный анализ.

\section{Этап 3}

Планирование. Представляется как разработка планов и распределение ресурсов для реализации стратегии и достижения целей. Методы для использования на данном этапе: сбалансированная система показателей (BSC), методы математической статистики, регрессионный анализ.

\section{Этап 4}

Мониторинг и контроль выполнения ключевых по- казателей эффективности и их отклонения от плана: методы математической статистики, метод трендового анализа.

\section{Этап 5}

Анализ и регулирование. Данный этап подразумевает анализ ключевых показателей эффективности образовательной системы и их отклонение от плана, разработка и реализация управляющих воздействий. Для реализации можно использовать корреляционный анализ, факторный анализ, регрессионный анализ, кластерный анализ, трендовый анализ, методы математической статистики, метод методы теории принятия решений.

Тот факт, что есть множество методов оценивания результативности управления, не дает эффективных возможностей использования данных методик для изучения контролирования эффективности образовательной системы. Применение каждой методики основано на предметной сфере задач. Кроме того, важны и ситуации, в которых происходит утверждение необходимых управленческих решений.

Благодаря формализованной постановке управленческих задач, можно применять средства вычислительной техники при изучении вероятных управляющих решений. Также это необходимо при установлении максимально эффективного решения.

\section{Зак^ючение}

На основе выполненного анализа моделей и алгоритмов управления крупными образовательными системами, систематизированы и классифицированы математические методы, применяемые в управлении деятельностью организаций. Обоснована целесообразность математических методов, применяемых при реализации каждой фазы эффективного управления образовательной системой, повышая открытость и прозрачность системы в целом.

\section{ЛИТЕРАТУРА}

1. Моргунов А.И., Ромашкова 0.Н. Информационная система для оценки результатов деятельности общеобразовательных организаций г. Москвы // Вестник РудН Серия «Информатизация образования». - 2015. - № 3. - С. 88-95.

2. Моргунов А.И. Информационная система управления эффективностью региональной образовательной системой // Экономика и управление. СПб: Чоу В0 «Санкт-Петербургский университет технологий управления и экономики», 2018. - № 5(151) - С. 68-74.

3. Моргунов А.И., Зайченко Д.С. Методика независимой оценки управления качеством образования крупной региональной образовательной системы // Сборник трудов XXIII Всероссийской научно-технической конференции студентов, молодых ученых и специалистов «Новые информационные технологии в научных исследованиях». - Рязань: РГРТУ, 2018. - С. 27-28.

4. Ромашкова 0.Н., Федин Ф.О., Ермакова Т.Н. Нейросетевая компьютерная модель для поддержки принятия решений в образовательных комплексах // Вестник Рязанского государственного радиотехнического университета. 2017. № 61. С. 54-59. 
5. Ромашкова 0.Н., Ермакова Т.Н. Моделирование информационных процессов управления образовательным комплексом // Вестник Российского университета дружбы народов. Серия: Информатизация образования. 2014. № 2. С. 122-129.

6. Ромашкова 0.Н., Ермакова Т.Н. Мониторинг качества образования в средней общеобразовательной организации с использованием современных средств информатизации // Вестник Российского университета дружбы народов. Серия: Информатизация образования. 2014. № 4. С. 10-17.

7. Моргунов А.И., Зайченко Д.С. Математическая модель оценивания качества управления региональной образовательной системы // Сборник научных трудов ІІ Международной научно-практической конференции «Новая наука: новые вызовы». - Краснодар: АНО ДПО «ИССиМ», 2018. - С. 50-54.

8. Моргунов А.И., Зайченко Д.С., Ромашкова 0.Н. Нейросетевая модель как инструмент поддержки принятия решений в образовательной системе // Естественные и технические науки. - 2019. - № 2. - С. 197-203.

(с) Моргунов Александр Игоревич (alex-260693@mail.ru), Ромашкова Оксана Николаевна (ox-rom@yandex.ru).

Журнал «Современная наука: актуальные проблемы теории и практики»
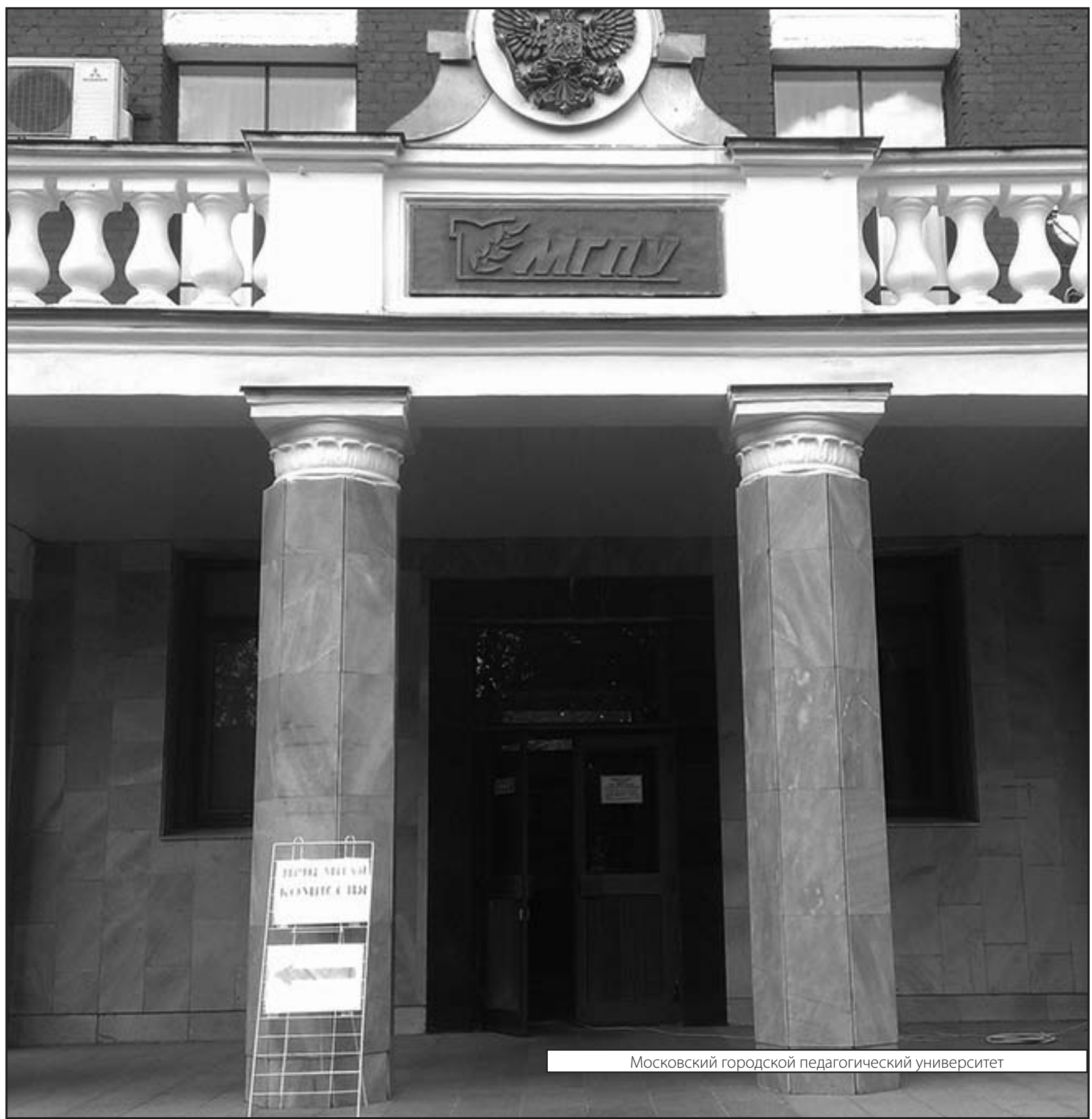